Marquette University

e-Publications@Marquette

College of Education Faculty Research and

Publications

Education, College of

4-1-1997

\title{
Relationship of Cognitive Style and Theoretical Orientation to Psychology Interns' Preferences for Supervision
}

Bruce T. Lochner

Texas Tech University

Timothy Melchert

Marquette University, timothy.melchert@marquette.edu

Accepted version. Journal of Counseling Psychology, Vol. 44, No. 2 (April 1997): 256-260. DOI. C) 1997 American Psychological Association. Used with permission.

Timothy P. Melchert was affiliated with Texas Tech University at the time of publication. 
Marquette University

e-Publications@Marquette

\section{Education Faculty Research and Publications/College of Education}

This paper is NOT THE PUBLISHED VERSION; but the author's final, peer-reviewed manuscript. The published version may be accessed by following the link in th citation below.

Journal of Counseling Psychology, Vol. 44, No. 2 (April 1997): 256-260. DOl. This article is (C American Psychological Association and permission has been granted for this version to appear in $\underline{\mathrm{e}}-$ Publications@Marquette. American Psychological Association does not grant permission for this article to be further copied/distributed or hosted elsewhere without the express permission from American Psychological Association.

\section{Relationship of Cognitive Style and Theoretical Orientation to Psychology Interns' Preferences for Supervision}

\section{Bruce T. Lochner}

Department of Psychology, Texas Tech University

Timothy P. Melchert

Department of Psychology, Texas Tech University;

Acknowledgement: Bruce T. Lochner is now at the Student Counseling Service, Texas A \& M University.

This work is based on Bruce T. Lochner's doctoral dissertation, conducted under the supervision of Timothy P. Melchert. We thank Rosemary Cogan, Susan Kashubeck, and Steve Richards for their support and assistance as dissertation committee members.

Clinical supervision is widely recognized as a fundamental component of professional training in the mental health field, and all of the major mental health specialties require that supervised clinical training be included in the programs that they accredit (American Medical Association, 1996; American Psychological Association [APA], Committee on Accreditation, 1995; Council on Social Work Education, 1994; Stevens-Smith, Hinkle, \& Stahmann, 1993). Models of the appropriate conduct of supervision have also existed since the beginning of psychoanalysis. 
Early supervision models were based on particular schools of psychotherapy and their corresponding theories of behavior change (e.g., psychoanalysis). More recently a range of cross-theoretical approaches (Russell, Crimmings, \& Lent, 1984) have been proposed, which Holloway (1992) has identified as being of two major types. Developmental models, the most popular of the two approaches, suggest that changes in trainees' behavior during the course of supervised clinical experience reflect an unfolding of developmental processes within trainees and that matching the supervision environment to the developmental level of student psychotherapists enhances their development. Social role models, the other approach identified by Holloway (1992), suggest that the supervisors' appropriate delineation of role boundaries and expectations within supervision promotes trainees' professional socialization, functioning, and understanding of their responsibilities.

Developmental models have become particularly popular in recent years, and most of these models suggest that beginning trainees learn best in an environment that is more task oriented and that features didactic instruction and structure, whereas advanced trainees' learn best in an environment that is more relationship oriented and that focuses on higher level clinical skills and personal issues (Gaoni \& Neumann, 1974; Hogan, 1964; Littrell, Lee-Borden, \& Lorenz, 1979; Stoltenberg, 1981; Stoltenberg \& Delworth, 1987). Several studies have found that beginning and advanced supervisees tend to report that the supervision they received is consistent with the prescriptions of these models (Heppner \& Roehlke, 1984; Hill, Charles, \& Reed, 1981; Stoltenberg, Pierce, \& McNeill, 1987; Swanson \& O'Saben, 1993; Worthington \& Roehlke, 1979; Worthington \& Stern, 1985). It has also been found, however, that supervisors generally perceive themselves as varying their supervision according to students' level of training in the manner advocated by developmental models of supervision (Glidden \& Tracev, 1992; Krause \& Allen, 1988; Miars et al., 1983; Wiley \& Ray, 1986; Worthington, 1984). Therefore, it is unclear whether the different supervisory styles reported by supervisees across levels of training reflect developmental changes or merely awareness of the different supervisory approaches that are used with them as they progress through their graduate training (Cross \& Brown, 1983; Holloway, 1987).

Neither developmental nor social role models emphasize the potential influence of individual differences in trainees other than developmental level, and there has also been little investigation of trainees' judgments regarding the supervisory approach that they believe would be most helpful to them. For example, cognitive style is an aspect of personality that has often been found to be related to students' and professionals' preferred learning style (for a review, see Myers \& McCaulley, 1985). Cognitive style refers to the manner in which people conceptually represent and organize their environment (Goldstein \& Blackman, 1978) and has most often been measured in the psychotherapy literature through use of the Jungian-based Myers-Briggs Type Indicator (MBTI; Myers \& McCaullev, 1985). Though the relationship between supervisees' cognitive styles and preferences for task-oriented or relationship-oriented supervision has not been investigated, several studies have found a relationship between cognitive style as measured by the four MBTI dimensions and both supervision process and outcome. For example, Schacht, Howe, and Berman (1989)found that professional psychologists scoring high on the Feeling dimension placed greater weight on the facilitative conditions, especially on empathy, when discriminating between their most and their least helpful past supervisors. Swanson and O'Saben (1993) found that the Sensing dimension was related to a trainee's need for benign support, the Introversion and Intuition dimensions were related to a need for respectful confrontation, and the Intuition and Extraversion dimensions were related to a need for behavioral monitoring.

Supervisees' theoretical orientation is another variable that is likely to have an impact on trainees' supervisory preferences. This possibility has not been examined empirically, but several studies have found that theoretical orientation also affects supervision process and outcome. For example, Friedlander and Ward (1984) found that trainees rated their humanistic and psychodynamic supervisors as being more interpersonally sensitive and less task oriented than were their cognitive-behavioral supervisors. Putney, Worthington, and McCullough 
(1992) found that psychology interns perceived their cognitive-behavioral supervisors as taking on a consultant role and a skill focus more often than did their humanistic, existential, and psychodynamic supervisors, who were perceived as more often playing the role of psychotherapist and focusing on client psychodynamics. Similarity in supervisor-supervisee theoretical orientation has also been found to be related to supervisees' positive impressions of supervision (Kennard, Stewart, \& Gluck, 1987; Putney et al., 1992; Schacht et al., 1989).

Most developmental models of supervision suggest that beginning psychotherapy trainees tend to prefer a structured, task-oriented style of supervision, whereas advanced trainees tend to prefer an interpersonally sensitive, relationship-oriented style of supervision. The literature reviewed above, however, has suggested that trainees' cognitive style and theoretical orientation may also affect their perceived needs and preferences regarding these types of supervisory styles. We therefore hypothesized that supervisees scoring high on the MBTI dimensions of Intuition, Feeling, and Perception would prefer an interpersonally sensitive, relationshiporiented style of supervision, whereas supervisees scoring high on the dimensions of Sensing, Thinking, and Judgment would have stronger preferences for structured, task-oriented supervision. We also hypothesized that supervisees adhering to more behavioral theoretical orientations would have greater preferences for taskoriented supervision and weaker preferences for relationship-oriented supervision compared with those adhering to less behavioral theoretical orientations. The study sample included only graduate students completing their predoctoral internships in psychology so that the variable of therapist developmental level could generally be controlled for (i.e., differences in developmental and experience levels were limited though not eliminated) and so that the participants in the study would have a significant amount of professional experience to draw from when indicating their theoretical orientations and preferences for clinical supervision.

\section{Method}

\section{Participants}

The participants were 106 interns who were completing APA-accredited internships in psychology. Most of the participants were women (65\%) and White/European-American (84\%); 7\% were African American, 5\% were Asian American, 2\% were Latino, and 2\% were designated as "other." The mean age of the sample was 32.37 $(S D=6.52$, range $=25-54)$. Ninety-eight percent had attended APA-accredited graduate programs in either clinical (83\%), counseling (14\%), or educational psychology (2\%). The participants were completing their internships at medical centers (31\%), Veterans Affairs facilities (20\%), state or private mental hospitals (13\%), community mental health clinics (10\%), university counseling centers (8\%), military facilities $(7 \%)$, consortia $(6 \%)$, school districts (2\%), corrections facilities (2\%), and a residential treatment center (1\%). These sample characteristics were nearly identical to those of the entire population of predoctoral psychology interns for the 1994-1995 academic year (Woerheide, 1996).

\section{Instruments}

We used the Keirsey Temperament Sorter (KTS; Keirsey \& Bates, 1984) to measure cognitive style in this study. Designed as a parallel instrument to the MBTI, the KTS is a 70-item questionnaire measuring the same dimensions as the MBTI, namely, Extraversion-Introversion (EI), Sensing-Intuition (SN), Thinking-Feeling (TF), and Judgment-Perception (JP). The El dimension concerns whether perception and judgment are primarily directed outwardly toward the world of people and things (Extraversion) or inwardly toward the world of ideas (Introversion); the SN dimension concerns the type of information one prefers to attend to, either objective information obtained through sensory experience (Sensing) or hunches and meanings about one's experience (Intuition); the TF dimension relates to the manner in which one arrives at conclusions, either objectively through logic and reasoning (Thinking) or subjectively through an awareness of feelings and personal values (Feeling); and the JP dimension describes the lifestyle one adopts, which is either decisive and orderly 
(Judgment) or flexible and spontaneous (Perception). We treated the four KTS scales as continuous variables in this study, each ranging from 0 to 1.

Tucker and Gillespie (1993) found that scores on the KTS and MBTI scales correlated between .68 and .84, which is similar to the reliability coefficients for these scales (split-half coefficients ranged from .82 to .86 , and testretest coefficients ranged from .56 to .93 over a 7-week interval; Myers \& McCaulley, 1985), indicating that the KTS is successful as a parallel version of the MBTI. Cronbach alpha coefficients for the four KTS scales obtained with the present sample ranged from .67 to .84 , which are similar to those obtained in previous research (.73.87; Waskel, 1995). Hundreds of studies using either the KTS or the MBTI have found substantial evidence for the validity of the four Jungian (Jung, 1923) dimensions for assessing personality and cognitive style and for identifying social environments that facilitate personal and professional growth (Devito, 1985; Myers \& McCaulley, 1985).

The Supervisory Styles Inventory-Trainee Version (SSI; Friedlander \& Ward, 1984) contains 25 scorable and 8 filler adjectives that represent three factor analytically derived independent dimensions of supervisory style. The Attractive scale pertains to the personal, interpersonally attractive aspect of supervision (e.g., warm, supportive,friendly); the Interpersonally Sensitive scale describes a relationship-oriented approach to supervision (e.g., therapeutic,invested, perceptive); and the Task-Oriented scale pertains to a structured, content-focused approach to supervision (e.g., goaloriented, didactic, evaluative). In this study, Cronbach alpha coefficients for the three SSI scales ranged from .73 to .87, which were similar to those found in the original research on the instrument. Friedlander and Ward found test-retest correlations ranging between .78 and .94 over a 2-week interval, and the scales discriminated well between supervisors of different theoretical orientations. Holloway $(1992,1995)$ described the SSI as having the best reliability and validity of any instrument designed specifically to measure aspects of the supervision relationship. We modified the instructions for completing the SSI for use in this study, however. Rather than ask respondents to indicate the supervisory style of their current or most recent supervisor, we asked them to indicate what they believed would be the characteristics of an ideal supervisor for them.

A brief demographics questionnaire inquired about respondents' gender, age, ethnicity, and type of graduatetraining program and internship they were completing. Global self-ascriptions were used for measuring therapists' theoretical orientations. We asked participants to indicate which theoretical orientation was most similar to their own, choosing from a list including psychodynamic-psychoanalytic, experiential (e.g., Gestalt, psychodrama), humanistic/person-centered, cognitive/cognitive-behavioral, behavioral, and family systems.

\section{Procedure}

We selected at random 81 fully accredited APA predoctoral internship sites in the United States from those listed in the directory of the Association of Postdoctorate and Psychology Internship Centers (1995). We sent a total of 410 questionnaire packets and cover letters explaining the nature of the study to the training directors at the selected sites and requesting their cooperation in distributing the packets to their interns. One hundred and fourteen usable questionnaires were returned. We excluded 8 of these from the data set because the respondents indicated family-systems theoretical orientations, which were too diverse in terms of behavioral emphasis to be used in the coding scheme described below. A follow-up survey of the training directors (response rate $=38 \%$ ) revealed that $13 \%$ had not distributed the packets to their interns, which resulted in an estimated sample size of 357 participants. Therefore, we estimated the minimum response rate for the study to have been $32 \%$, although the actual rate would have been higher if a disproportionately large number of the training directors who did not respond to the follow-up survey had also not distributed the questionnaire packets to their interns. We assured the participants that their responses to the questionnaire would be kept confidential and that their anonymity would be protected. 


\section{Results}

The mean scores obtained by the sample on the KTS and the SSI scales are found in Table 1. In addition, the proportions of interns identifying with the various theoretical orientations were as follows: $44 \%$ psychoanalyticpsychodynamic ( $n=47), 37 \%$ cognitive/cognitive-behavioral $(n=39), 10 \%$ humanistic/client-centered $(n=11)$, $7 \%$ behavioral $(n=7)$, and $1 \%$ experiential $(n=1)$. We assigned interns to one of two groups on the basis of the extent to which their identified theoretical orientation emphasized behavior (see Putney et al., 1992). The more behavioral group consisted of 46 interns who identified with cognitive/cognitive-behavioral or behavioral theoretical orientations, and the less behavioral group consisted of 59 interns who identified with psychoanalytic-psychodynamic, humanistic/client-centered, or experiential theoretical orientations.

Table 1

Correlations Between Supervisory Preference and Cognitive Style

\begin{tabular}{lccccccccc}
\hline \multicolumn{1}{c}{ Variable } & $M$ & $S D$ & 1 & 2 & 3 & 4 & 5 & 6 & 7 \\
\hline 1. Attractive & 5.81 & 0.89 & - & & & & & & \\
2. Interpersonally sensitive & 5.70 & 0.65 & $.62^{* * *}$ & - & & & &. & \\
3 Task oriented & 4.61 & 0.86 & $.28^{* *}$ & $.19^{*}$ & - & & & & \\
4. Extraversion-Intraversion & 0.40 & 0.23 & -.13 & .03 & .09 & - & & & \\
5. Sensing-Intuition & 0.61 & 0.17 & .06 & $.19^{*}$ & $-.52^{* * *}$ & .09 & - & & \\
6. Thinking-Feeling & 0.60 & 0.22 & $.20^{*}$ & $.21^{*}$ & -.09 & -.09 & $.28^{* *}$ & - & \\
7. Judgment-Perception & 0.61 & 0.17 & -.12 & .04 & $-.33^{* * *}$ & -.10 & $.52^{* * *}$ & $.22^{*}$ & - \\
\hline$p<.05 . \quad{ }^{* *} p<.01 .{ }^{* * *} p<.001$. & & & & & & & &
\end{tabular}

Table 1. Correlations Between Supervisory Preference and Cognitive Style

\begin{tabular}{|l|l|l|l|l|l|l|l|l|l|}
\hline Variable & $\mathrm{M}$ & $\mathrm{SD}$ & 1 & 2 & 3 & 4 & 5 & 6 & 7 \\
\hline I. Attractive & 5.81 & 0.89 & - & & & & & & \\
\hline 2. Interpersonally sensitive & 5.70 & 0.65 & $.62^{* * *}$ & - & & & & & \\
\hline 3 Task oriented & 4.61 & 0.86 & $.28^{* *}$ & $.19^{*}$ & - & & & & \\
\hline 4. Extraversion-Intraversion & 0.40 & 0.23 & -.13 & .03 & .09 & - & & & \\
\hline 5. Sensing-Intuition & 0.61 & 0.17 & .06 & $.19^{*}$. & $-.52^{* * *}$ & .09 & - & & \\
\hline 6. Thinking-Feeling & 0.60 & 0.22 & $.20^{*}$ & $21^{*}$ & -.09 & -.09 & $.28^{* *}$ & - & \\
\hline 7. Judgment-Perception & 0.61 & 0.17 & -.12 & .04 & $-.33^{* * *}$ & -.10 & $.52^{* * *}$ & $.22^{*}$ & - \\
\hline
\end{tabular}

$* p<.05 .{ }^{* *} p<.01 .{ }^{* * *} p<.001$.

We performed a canonical correlation analysis to simultaneously assess the interrelationships among the supervisory preferences (the criterion variables) and the cognitive style and the behavioral emphasis of participants' theoretical orientations (the predictor variables). Two significant canonical functions were extracted from the analysis. The canonical correlation for the first function was .65 $(p<.001)$ and for the second function, $.30(p<.05)$. The redundancy coefficient for the criterion variables was .14, indicating that $14 \%$ of the variance in cognitive style plus behavioral emphasis of theoretical orientation was accounted for by variance in supervision preferences. The redundancy coefficient for the predictor variables was .16, indicating that $16 \%$ of the variance in supervisory preferences was accounted for by variance in cognitive style and behavioral emphasis of theoretical orientation. These findings indicate that supervisory preferences are significantly related to cognitive style and theoretical orientation.

The canonical loadings for Function 1 indicate that preferences for task-oriented supervision (and less interpersonally sensitive supervision) are associated with high Sensing (low Intuition) scores and also with high Judgment (low Perception) and high Thinking (low Feeling) scores and with a theoretical orientation that emphasizes behavior (see Table 2). The canonical loadings for Function 2 indicate that low supervisory preferences for attractiveness are associated with high Thinking (low Feeling), high Extraversion (low 
Introversion), and high Perception (low Judgment) scores.

Table 2

Canonical Correlation Analysis of Supervisory

Preferences, Cognitive Style, and Theoretical Orientation

\begin{tabular}{lrc}
\hline & \multicolumn{2}{c}{ Canonical loadings } \\
\cline { 2 - 3 } Variable & Function 1 & Function 2 \\
\hline \multicolumn{1}{c}{ Supervisory preferences } \\
Attractive & .03 & -.86 \\
Interpersonally sensitive & -.42 & -.22 \\
Task oriented & .81 & .04 \\
\hline
\end{tabular}

\begin{tabular}{lrr}
\hline \multicolumn{3}{c}{ Cognitive style and theoretical orientation } \\
EI & .13 & -.63 \\
SN & -.91 & -.17 \\
TF & -.30 & -.69 \\
JP & -.57 & .30 \\
Behavioral emphasis & .67 & -.02 \\
\hline
\end{tabular}

Table 2. Canonical Correlation Analysis of Supervisory Preferences, Cognitive Style, and Theoretical Orientation

\begin{tabular}{|l|l|l|l|}
\hline & & & \\
\hline Variable & & Canonical loadings & \\
\hline & & Function 1 & Function 2 \\
\hline Attractive & Supervisory preferences & & \\
\hline Interpersonally sensitive & & 03 & -.86 \\
\hline Task oriented .81.04 & & -.42 & -.22 \\
\hline & Cognitive style and theoretical orientation & & \\
\hline EI & & .13 & \\
\hline SN & & -.91 & -.63 \\
\hline TF & & -.30 & -.17 \\
\hline JP & & -.57 & -.69 \\
\hline Behavioral emphasis & & .67 & .30 \\
\hline
\end{tabular}

Note. El = Extraversion-Introversion; SN = Sensing-Intuition; TF = Thinking-Feeling; JP = Judgment-Perception. The low behavioral-emphasis group included psychoanalytic-psychodynamic, humanistic/client-centered, and experiential theoretical orientations; the high behavioral-emphasis group included cognitive/cognitive-behavioral and behavioral theoretical orientations.

\section{Discussion}

This study tested several hypotheses predicting that the general manner in which psychology interns conceptualize and organize their experience (i.e., their cognitive style) and the manner in which they conceptualize psychotherapy (i.e., their theoretical orientation) are related to supervisees' preferences and needs regarding their clinical supervision. The hypotheses of the study were consistently supported. Interns with relatively high scores on the dimensions of Sensing, Thinking, and Judgment and those whose theoretical orientations were more behavioral tended to indicate that their ideal supervisor would be task oriented, whereas those with the opposite pattern of scores tended to indicate that their ideal supervisor would be more interpersonally attractive.

Most models of counselor development and supervision have not emphasized the individual differences of trainees other than their developmental levels, although some have noted the potential significance of some individual differences. For example, Stoltenberg (1981) suggested that differences in sensory orientation (i.e., 
auditory vs. visual), values, and motivation should be considered when designing developmentally appropriate supervision environments, and Loganbill, Hardy, and Delworth (1982) advised that trainees' learning styles should be factored into methods of teaching. Recently, Holloway (1995) also identified learning style and learning needs as influences on trainees' experiences of supervision. None of the models, however, has emphasized supervisees' cognitive style or theoretical orientation as potentially significant influences on supervisees' judgments regarding the type of supervision that would be most helpful to them.

Stage models of counselor development in particular have implied that supervisees' preferences for taskoriented supervision indicate low levels of professional development, whereas preferences for relationshiporiented supervision indicate more advanced levels of professional development. Our study, however, found that individual differences in the cognitive styles and theoretical orientations of psychology interns, a group that is presumably at a relatively high level of professional development, are significantly related to their preferences for these two supervisory styles. These findings are consistent with numerous studies from other fields that have also found that the KTS and the MBTI dimensions are related to students' and a variety of professionals' preferred learning styles (for reviews, see Murphy, 1992; Myers \& McCaulley, 1985).

The results of this study need to be interpreted in light of several limitations. First, participation in the study was contingent on the willingness of training directors to distribute the research packets, and it is possible that this procedure introduced a selection bias into the sample. Second, some theoretical orientation groups were small, which makes their representativeness uncertain. It also remains unclear whether supervisees' development is enhanced by the supervisory characteristics that they believe will be most helpful to them. If future research finds that matching supervisory styles to supervisees' preferences does result in more positive training outcomes, however, current models of psychotherapist training will need to be reconsidered.

\section{References}

American Medical Association. (1996). Graduate medical education directory. (1996-1997 ed.). Chicago: Author. American Psychological Association, Committee on Accreditation. (1995). Guidelines and principles for accreditation of programs in professional psychology. Washington, DC: Author.

Association of Postdoctorate and Psychology Internship Centers. (1995). Directory: Internship and postdoctoral programs in professional psychology(24th ed.). Washington, DC: Author.

Council on Social Work Education. (1994). Handbook of accreditation standards and procedures. Alexandria, VA: Author.

Cross, D. G., \& Brown, K. (1983). Counselor supervision as a function of trainee experience: Analysis of specific behaviors. Counselor Education and Supervision, 22, 333-341.

Devito, A. J. (1985). Review of the Myers-Briggs Type Indicator. In O. K.Buros (Ed.), The ninth mental measurements yearbook (pp. 1030-1032). Highland Park, NJ: Gryphon.

Friedlander, M. L., \& Ward, L. G. (1984). Development and validation of the Supervisory Styles Inventory. Journal of Counseling Psychology, 31, 541-557.

Gaoni, B., \& Neumann, M. (1974). Supervision from the point of view of the supervisee. American Journal of Psychotherapy, 24, 108-114.

Glidden, C. E., \& Tracey, T. J. (1992). A multidimensional scaling analysis of supervisory dimensions and their perceived relevance across trainee experience levels. Professional Psychology: Research and Practice, 23, 151-157.

Goldstein, K. M., \& Blackman, S. (1978). Cognitive style: Five approaches to theory and research. San Francisco: Jossey-Bass. \.

Heppner, P. P., \& Roehlke, H. J. (1984). Differences among supervisees at different levels of training: Implications for a developmental model of supervision. Journal of Counseling Psychology, 31, 76-90.

Hill, C. E., Charles, D., \& Reed, K. G. (1981). A longitudinal analysis of changes in counseling skills during doctoral training in counseling psychology. Journal of Counseling Psychology, 28, 428-436. 
Hogan, R. A. (1964). Issues and approaches in supervision. Psychotherapy: Theory, Research, and Practice, 1, 139-141.

Holloway, E. L. (1987). Developmental models of supervision: Is it development?Professional Psychology: Research and Practice, 18, 209-216.

Holloway, E. L. (1992). Supervision: A way of teaching and learning. In S. D.Brown \& R. W.Lent (Eds.), Handbook of counseling psychology (2nd ed., (pp. 117-214). New York: Wiley.

Holloway, E. L. (1995). Clinical supervision: A systems approach. Thousand Oaks, CA: Sage.

Jung, C. G. (1923). Psychological types. London: Pantheon Books. \.

Keirsey, D., \& Bates, M. (1984). Please understand me. Del Mar, CA: Gnosology Books.

Kennard, B. D., Stewart, S. M., \& Gluck, M. R. (1987). The supervision relationship: Variables contributing to positive versus negative experiences. Professional Psychology: Research and Practice, 18, 172-175.

Krause, A. A., \& Allen, G. J. (1988). Perceptions of counselor supervision: An examination of Stoltenberg's model from the perspective of supervisor and supervisee. Journal of Counseling Psychology, 35, 77-80.

Littrell, C., Lee-Borden, N., \& Lorenz, J. (1979). A developmental framework for counseling supervision. Counselor Education and Supervision, 18, 129-136.

Loganbill, C., Hardy, E., \& Delworth, U. (1982). Supervision: A conceptual model. The Counseling Psychologist, 10, 3-42.

Miars, R. D., Tracey, T. J., Ray, P. B., Cornfield, J. L., O'Farrell, M., \& Gelso, C. J. (1983). Variation in supervision process across trainee experience levels. Journal of Counseling Psychology, 30, 403-412.

Murphy, E. (1992). The developing child: Using Jungian types to understand children. Palo Alto, CA: Consulting Psychologists Press.

Myers, I. B., \& McCaulley, M. H. (1985). A guide to the development and use of the Myers-Briggs Type Indicator. Palo Alto, CA: Consulting Psychologists Press.

Putney, M. W., Worthington, E. L., \& McCullough, M. E. (1992). Effects of supervisor and supervisee theoretical orientation, and supervisor-supervisee matching on interns' perceptions of supervision. Journal of Counseling Psychology, 39, 258-265.

Russell, R. K., Crimmings, A. M., \& Lent, R. L. (1984). Counseling supervision and training: Theory and research. In S.Brown \& R. L.Lent (Eds.), Handbook of counseling psychology (pp. 625-681). New York: Wiley.

Schacht, A. J., Howe, E., \& Berman, J. J. (1989). Supervisor facilitative conditions and effectiveness as perceived by thinking- and feeling-type supervisees. Psychotherapy, 26, 475-483.

Stevens-Smith, P., Hinkle, J. S., \& Stahmann, R. F. (1993). A comparison of professional accreditation standards in marriage and family counseling and therapy. Counselor Education and Supervision, 33, 116-126.

Stoltenberg, C. (1981). Approaching supervision from a developmental perspective: The counselor complexity model. Journal of Counseling Psychology, 28, 9-65.

Stoltenberg, C., \& Delworth, U. (1987). Supervising counselors and therapists. San Francisco: Jossey-Bass.

Stoltenberg, C. D., Pierce, R. A., \& McNeill, B. W. (1987). Effects of experience on counselor needs. The Clinical Supervisor, 5, 23-32.

Swanson, J. L., \& O'Saben, C. L. (1993). Differences in supervisory needs and expectations by trainee experience, cognitive style, and program membership. Journal of Counseling and Development, 71, 457-464.

Tucker, I. F., \& Gillespie, B. V. (1993). Correlations among three measures of personality type. Perceptual and Motor Skills, 77, 650.

Waskel, S. A. (1995). Temperament types: Midlife death concerns, demographics, and intensity of crisis. Journal of Psychology, 129, 221-233.

Wiley, M., \& Ray, P. (1986). Counseling supervision by developmental level. Journal of Counseling Psychology, 33, 439-445.

Woerheide, K. (1996, Winter). Summary of 1994-1995 annual report data for doctoral and internship programs. Capsule (pp. 5-8). Washington, DC: American Psychological Association, Committee on Accreditation.

Worthington, E. L. Jr. (1984). Empirical investigation of supervision of counselors as they gain experience. Journal of Counseling Psychology, 31, 63-75. 
Worthington, E. L. Jr., \& Roehlke, H. J. (1979). Effective supervision as perceived by beginning counselors-intraining. Journal of Counseling Psychology, 26, 64-73.

Worthington, E. L. Jr., \& Stern, A. (1985). Effects of supervisor and supervisee degree level and gender on the supervisory relationship. Journal of Counseling Psychology, 32, 252-262.

Submitted: July 22, 1996 Revised: November 4, 1996 Accepted: November 4, 1996

This publication is protected by US and international copyright laws and its content may not be copied without the copyright holders express written permission except for the print or download capabilities of the retrieval software used for access. This content is intended solely for the use of the individual user.

Source: Journal of Counseling Psychology. Vol. 44. (2), Apr, 1997 pp. 256-260)

Accession Number: 1997-08136-014

Digital Object Identifier: 10.1037/0022-0167.44.2.256 